D) Check for updates

Cite this: Food Funct., 2018, 9, 2774

\title{
Black pepper-based beverage induced appetite- suppressing effects without altering postprandial glycaemia, gut and thyroid hormones or gastrointestinal well-being: a randomized crossover study in healthy subjects
}

\author{
Yoghatama Cindya Zanzer, (D) *a Merichel Plaza, (D) ${ }^{b, c}$ Anestis Dougkas, (D) a,d \\ Charlotta Turner (iD ${ }^{c}$ and Elin Östman (iD ${ }^{a}$
}

\begin{abstract}
Pleiotropic effects of spices on health, particularly on glucose metabolism and energy regulation, deserve further clinical investigation into their efficacy. The aim of the current study was to evaluate whether consumption of a black pepper-based beverage (BPB) preload containing $20 \mathrm{mg}$ gallic acid equivalent (GAE) would exert any effect on postprandial glycaemia, appetite sensations, gut hormones, thyroid function, and gastrointestinal well-being after a white wheat bread (WWB) challenge meal containing $50 \mathrm{~g}$ available carbohydrates $(\mathrm{CHO})$ compared to a control beverage. Sixteen healthy subjects (10 men; 6 women; $26 \pm$ 0.9 years; BMI $22.93 \pm 0.53 \mathrm{~kg} \mathrm{~m}^{-2}$ ) completed a randomized, crossover intervention study. The BPB's bioactive compounds were characterized using ultra high-performance liquid chromatography coupled to a quadrupole time-of-flight mass spectrometer with an electrospray ionization source (UHPLC-DAD-ESI-QTOF-MS). Nine compounds tentatively identified in BPB include: dihydroxybenzoic acid hexoside-pentoside, decaffeoyl-acteoside, cynaroside A, apigenin 6,8-di-C-hexoside, luteolin 6-Chexoside-8-C-rhamnoside, apigenin 8-C-hexoside-C-deoxyhexoside, kaempferol 3-rhamnoside-4'xyloside, apigenin 7-neohesperidoside, and apigenin-8-C-arabinopyranoside-2"-rhamnoside. Blood glucose and serum insulin responses, insulin sensitivity and $\beta$-cell function were not affected during the acute intervention with BPB. Neither were effects on gastrointestinal well-being observed after BPB. However, BPB modulated overall acute appetite by lowering 'hunger', 'desire to eat', and 'prospective consumption', and increasing 'satiety' and 'fullness'. In contrast, there were no changes in gut (peptide tyrosine-tyrosine [PYY] and glucagon-like peptide-1 [GLP-1]) and thyroid (triiodothyronine [T3] and thyroxine [T4]) hormones after BPB compared to the control beverage. In conclusion, inclusion of BPB prior to the WWB challenge meal might be beneficial for appetite modulation, but we did not find supporting evidence in glycaemia, gut and thyroid hormones. Further studies are needed to elucidate the mechanisms of appetite-reducing pungent spices, such as black pepper.
\end{abstract}

Received 31st October 2017 Accepted 16th April 2018 DOI: 10.1039/c7fo01715d rsc.li/food-function

\section{Introduction}

The prevalence of overweight and obesity has increased indiscriminately in all parts of the world causing economic and

\footnotetext{
${ }^{a}$ Food for Health Science Centre, Lund University, P.O. Box 124, Lund SE-22100, Sweden.E-mail: yoghatama.cindya_zanzer@food-health-science.lu.se, y.c.zanzer@icloud.com; Tel: +46-46-222-8319

${ }^{b}$ Department of Analytical Chemistry, Physical Chemistry and Chemical Engineering, Faculty of Biology, Environmental Sciences and Chemistry, Universidad de Alcalá, Ctra. Madrid-Barcelona Km. 33.600, 28871 Alcalá de Henares, Madrid, Spain ${ }^{c}$ Department of Chemistry, Centre for Analysis and Synthesis, Lund University, P.O. Box 124, Lund SE-22100, Sweden

${ }^{d}$ Institute Paul Bocuse Research Centre, Chateu du Vivier, BP 25-69131, Ecully Cedex, France
}

health burdens. ${ }^{1,2}$ Hence, a better understanding of appetite regulation is crucial, not only for managing obesity but also its associated disorders. Humans spend the majority of their day in a postprandial state, with fluctuating glycaemia and lipaemia after every meal (breakfast, lunch, dinner, and inter-meal snacking). Given that energy balance is a dynamic process, acute management of appetite and controlling day-to-day glycaemia or lipaemia are important to avoid homeostatic perturbations with long-term consequences for risk of metabolic diseases and their associated complications. ${ }^{3,4}$

Evidence shows that food-derived polyphenols have beneficial effects on metabolic diseases. ${ }^{5}$ Plant-derived phenolic compounds have been shown to modulate blood glucose regulation through inhibition of $\alpha$-glucosidase, $\alpha$-amylase as well 
as the intestinal transporters, Na-dependent glucose co-transporter-1 (SGLT1) and facilitated Na-independent glucose transporter-2 (GLUT2). ${ }^{6}$ Although appetite regulation is governed by complex signaling in the peripheral and central systems, its association with glucose metabolism adds complexity to energy intake and expenditure. It has been shown that consumption of low glycaemic index foods could influence shortterm control of appetite and satiety. ${ }^{7,8}$ In addition, emerging evidence shows that phenolic compounds potentially influence appetite regulation and body weight. ${ }^{9}$ Furthermore, certain polyphenols modulate cellular energy expenditure and thyroid hormone activation $^{10}$ and thus, might be beneficial for maintaining energy balance. ${ }^{11}$

Among others, culinary spices are considered to be polyphenol-rich sources owing to pleiotropic effects associated with health-benefits. ${ }^{12}$ Spices have been used mainly to stimulate our senses with flavors, heating and burning sensations. Since flavor is considered as the primary driver of food intake, spices with distinctive characteristics could alter flavor and therefore food intake. ${ }^{13}$ Capsaicin - originating from red pepper - is the most studied among the spice derived bioactives with regards to thermogenic and satiating properties. ${ }^{14,15}$ However, discrepancies exist among the aforementioned effects due to differences in study design, such as short vs. long-term intervention, and in participant and food treatment characteristics. ${ }^{14,15}$ Other pungent spices, such as black pepper have been suggested to potentially affect glycaemia, appetite and energy intake regulation, ${ }^{16-18}$ yet evidence in humans is limited and thus warrants further investigation.

The primary objective of the present study was to examine the postprandial effect of a black pepper-based beverage (BPB) on glycaemia and the secondary objectives were to investigate its effects on appetite, gastrointestinal well-being, gut hormones (peptide tyrosine-tyrosine [PYY] and glucagon-like peptide-1 [GLP-1]) as well as thyroid hormones (triiodothyronine [T3] and thyroxine [T4]) postprandially after a white wheat bread (WWB) challenge in healthy adults.

\section{Materials and methods}

\subsection{Ethical aspects}

This study was conducted according to the Guidelines laid down in the Declaration of Helsinki and ethical approval was given by the Regional Ethical Review Board in Lund, Sweden (2013/862). This study was a sub-study conducted independently from the main study, which was registered under http:// clinicaltrials.gov as NCT02035241. Written informed consent was obtained from participants and they were aware of the possibility of withdrawing from the study at any time they desired.

\subsection{Participants and recruitment process}

Participants were recruited from Lund city area through local advertising at Lund University and in public places such as a sport center, canteen, and supermarket between January-
February 2014. The inclusion criteria were: BMI $>20$ and $<28 \mathrm{~kg} \mathrm{~m}^{-2}$; hemoglobin ( $\left.\mathrm{Hb}\right)$ for male (134-170 $\mathrm{g} \mathrm{L}^{-1}$ ) and female (117-153 $\left.\mathrm{g} \mathrm{L}^{-1}\right)$; ferritin for male $\left(27-365 \mu \mathrm{g} \mathrm{L}^{-1}\right)$ and female (13-148 $\left.\mu \mathrm{g} \mathrm{L}^{-1}\right)$. Individuals were excluded if they were $<18$ years old, or reported any of the following: smoking or chewing tobacco (snuss); a vegetarian or vegan diet; being stressed by venous blood sampling or previous experience of cannulation difficulties; taking dietary supplements or receiving any drug treatment; pregnancy or breastfeeding; having a diagnosis of liver disease or diabetes mellitus; having certain food allergies and having gastrointestinal related disorder/ diseases.

\subsection{Study design and intervention}

A randomized, cross-over design was used for this study with at least 1-week separation between experimental visits. The randomization was conducted with permuted block design with a block size of four. The study was carried-out at the Food for Health Laboratory at Food for Health Science Center, Lund University, Sweden. Subjects underwent a low-phenolic diet $48 \mathrm{~h}$ prior to and $24 \mathrm{~h}$ following the experimental visit. The low-phenolic diet consisted of unflavored dairy products, white wheat bread, red meat, fish, eggs, pasta (not whole grain), potatoes (without peel), and white rice. Participants were obliged to avoid fruits, vegetables, nuts, seeds, chocolate, and whole grain products as well as beer, wine, cider, coffee, and tea. During cooking, the use of butter was encouraged rather than vegetable oils, and onions and garlic were avoided. Adherence to the low-phenolic diet was followed-up with food records filled-out by the participants. Participants were instructed to avoid alcohol and excessive physical exercise two days before each experimental visit, and the adherence was evaluated using physical activity questionnaire records. Additionally, no probiotics or antibiotics should have been consumed for the entire experimental period or the two preceding weeks. Subjects underwent $10 \mathrm{~h}$ fasting prior to the experimental visit and arrived fasting in the morning (at 07:45 h). Upon arrival, 10 min supine rest was compulsory and subsequently, a catheter (BD Venflon ${ }^{\mathrm{TM}}$ Pro, Becton Dickinson and Company, USA) was placed in the forearm and both venous and capillary fasting blood samples were taken for baseline measurements. Afterwards, the black pepper-based beverage (BPB) or the control beverage was served and consumed within $5 \mathrm{~min}$. Ten min later, a portion of white wheat bread (WWB) containing $50 \mathrm{~g}$ available carbohydrates (CHO) was served and requested to be consumed in entirety within $10 \mathrm{~min}$. The $15 \mathrm{~min}$ given since the first sip of BPB would allow the liquid to reach the small bowel, thus favoring the interaction of the drink components with the digestive system. ${ }^{19}$ Blood samples were then taken at 15, 30, 45, 60, 90, 120 , and $180 \mathrm{~min}$ after the start of WWB consumption. Appetite ratings and gastrointestinal well-being were assessed using standard subjective $100 \mathrm{~mm}$ visual analogue scales (VAS) immediately after each blood sampling. Before the experimental trials, a training session for participants on the use of the VAS software was arranged after they signed an informed 


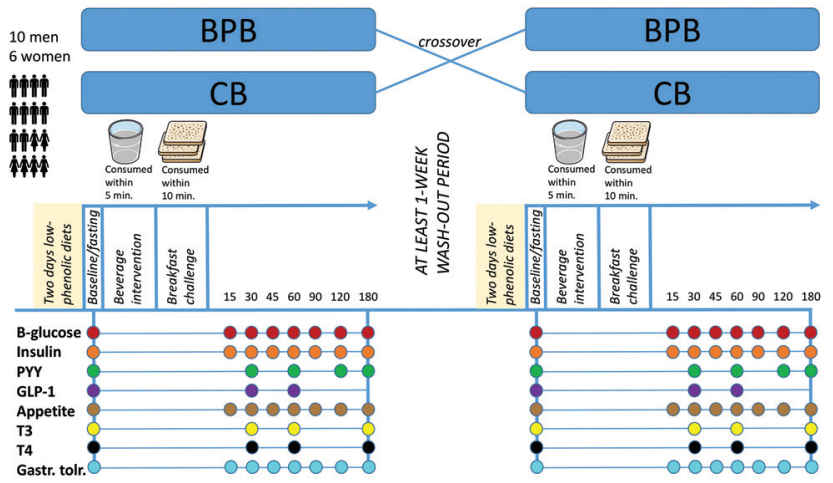

Fig. 1 Schematic outline of the study design.

consent. A schematic representation of the study design is depicted in Fig. 1.

\subsection{Intervention beverage and standard bread}

BPB was made from flavored water mixed with an extract of black pepper. The flavored water was made from a mix of water and non-caloric $(4 \mathrm{~kJ}$ per $100 \mathrm{~mL})$ strawberry marula flavoured squash concentrate (FunLight, Procordia-Orkla, Sweden) diluted $5: 1$. This was used as the basis of both the test and the control beverages to enhance the taste. Twenty $g$. of black pepper was extracted with heated flavored water $\left(90{ }^{\circ} \mathrm{C}, 3 \mathrm{~min}\right)$. The liquid part of $100 \mathrm{ml}$ extract was then diluted with $900 \mathrm{ml}$ flavored water and from that, $220 \mathrm{ml}$ was used as the intervention drink (BPB). The total polyphenol amount in $220 \mathrm{ml}$ BPB was $20 \mathrm{mg}$ gallic acid equivalent (GAE). The total polyphenol concentration was estimated from a direct analysis of extract by the Folin-Ciocalteau method. ${ }^{20}$ Flavored water only was used as the control beverage. Standard WWB (JätteFranska, Pågen, Malmö, Sweden) of one batch was purchased from a local supermarket. The macronutrient composition of standard WWB (113.5 g) given was $295 \mathrm{kcal}, 3.97 \mathrm{~g}$ fat, $50 \mathrm{~g}$ carbohydrate and $9.63 \mathrm{~g}$ protein, according to the nutrition label.

\subsection{Characterization of phenolic compounds by UHPLC-DAD-ESI-QTOF-MS}

Phenolic compounds in the BPB were analyzed by ultra-high performance liquid chromatography (UHPLC) (Waters Acquity UPLC chromatographic system, Waters Corp., Manchester, UK) with a photodiode array detector (DAD) and a quadrupole and orthogonal acceleration time-of-flight tandem mass spectrometer Xevo G2 qTOF with electrospray ionization (ESI) (Waters MS Technologies, Manchester, UK). The system was controlled by Waters ${ }^{\circledR}$ Empower ${ }^{\mathrm{TM}}$ Chromatography software, while MassLynx $^{\mathrm{TM}}$ (V 4.1, SCN 779, Waters Corp., Manchester, UK) was used for the MS data acquisition and treatment. Five microliters of BPB were injected onto a Waters Acquity UPLC BEH-C18 column $(2.1 \times 100 \mathrm{~mm}, 1.7 \mathrm{~m} 110 \AA$; Waters Corporation, Milford, MA). The mobile phase consisted of (A) water and (B) methanol, both containing $0.5 \%(\mathrm{v} / \mathrm{v})$ formic acid. The column temperature was $50{ }^{\circ} \mathrm{C}$ and the flow rate $300 \mu \mathrm{L} \mathrm{min}{ }^{-1}$. Phenolics were eluted according to the following: $0 \mathrm{~min}, 5 \% \mathrm{~B} ; 1 \mathrm{~min}, 5 \% \mathrm{~B} ; 7 \mathrm{~min}, 50 \% \mathrm{~B} ; 11 \mathrm{~min}, 50 \% \mathrm{~B}$; $11.5 \mathrm{~min} 5 \% \mathrm{~B} ; 15 \mathrm{~min}, 5 \% \mathrm{~B}$. The diode array detector recorded the spectra from 200 to $500 \mathrm{~nm}$. The mass spectrometer was operated in both ionization modes, negative and positive ESI interface using the following parameters: capillary voltage, $3 \mathrm{kV}$; cone voltage, $30 \mathrm{~V}$; source temperature, $120{ }^{\circ} \mathrm{C}$; and desolvation temperature, $400{ }^{\circ} \mathrm{C}$. Nitrogen was used as both cone gas $\left(50 \mathrm{~L} \mathrm{~h}^{-1}\right)$ and desolvation gas $\left(1000 \mathrm{~L} \mathrm{~h}^{-1}\right)$. Full-scan UHPLC-qTOF-MS spectra were obtained by scanning in the range $m / z 50-1200$. The mass spectrometer was calibrated using a solution of sodium formate. Data were collected in centroid mode and all the analyses were performed with leucine-enkephalin $\left(10 \mu \mathrm{L} \mathrm{min}{ }^{-1}, 2 \mathrm{ng} \mu \mathrm{L}^{-1}\right)$ in the lockspray. $\mathrm{MS}^{\mathrm{E}}$ was performed with the low collision energy set off and the high collision energy ramped from 15 to $60 \mathrm{~V}$, in order to obtain a full scan of accurate mass fragment, precursor ion and neutral loss information. The tentative identification of phenolic compounds was performed by matching the obtained accurate mass values and the theoretical mass values (error less than $3.3 \mathrm{ppm}$ ) in the database FooDB (http://foodb.ca/). The experimental MS/MS spectra obtained for each phenolic compound were compared to those described both in FooDB database and literature, and/or predicted MS/MS spectra obtained in CFM-ID (http://cfmid.wishartlab.com).

\subsection{Anthropometric, biochemicals, appetite sensations and gastrointestinal well-being measurements}

Body weight and composition were measured using the bioimpedance method (BC-418MA, TANITA). Finger-prick capillary samples were collected for the analysis of blood glucose (HemoCue ${ }^{\circledR}$ blood glucose, HemoCue AB, Ängelholm, Sweden) and $\mathrm{Hb}$ (HemoCue ${ }^{\circledR} \mathrm{Hb} 201 \mathrm{DM}$, HemoCue AB, Ängelholm, Sweden). To obtain serum, venous blood samples were collected in a SST ${ }^{\mathrm{TM}}$ BD Vacutainer ${ }^{\circledR}$ (Becton Dickinson, Plymouth, UK) and allowed to stand for $30 \mathrm{~min}$ for clotting before undergoing centrifugation $(3000 \mathrm{rpm}$ for $10 \mathrm{~min}$ at $4{ }^{\circ} \mathrm{C}$ ). In addition, blood samples were collected into K2-EDTA BD Vacutainer® (Becton Dickinson, Plymouth, UK) to obtain plasma (4000 rpm for $10 \mathrm{~min}$ at $4{ }^{\circ} \mathrm{C}$ ). An inhibitor of dipeptidyl peptidase IV (Diprotin A/ile-pro-ile, Sigma-Aldrich, St Louis, MO) and Pefabloc (Roche Diagnostics, Mannheim, Germany) were added to the plasma collection tubes for later determination of PYY and GLP-1. Serum insulin (Insulin ELISA Mercodia, Uppsala, Sweden), plasma PYY (Human PYY EIA YK080, Yanaihara Inst. Inc., Shizuoka, Japan), plasma GLP-1 (GLP-1 Total ELISA kit, Millipore Co., St Charles, MS, USA), plasma T3 (univ. hospital routine analysis), plasma T4 (univ. hospital routine analysis), and plasma ferritin (univ. hospital routine analysis) were determined accordingly. Aliquots were immediately stored at $-80^{\circ} \mathrm{C}$ until further analysis. Absorbance readings for the respective biomarkers were performed on an integrated immunoassay analyzer (SPECTROstar-Nano BMG LabTech GmbH, Ortenberg, Germany). Subjective appetite profile and gastrointestinal well- 
being were measured electronically in provided laptops with the use of $100 \mathrm{~mm}$ VAS. Appetite profiles measured include ratings of 'hunger' (How hungry do you feel?), 'desire to eat' (How strong is your desire to eat?), 'satiety' (How satiated [i.e. pleasantly satisfied] are you?), 'fullness' (How full do you feel?), and 'prospective consumption' (How much food do you think you could eat right now?), all anchored by the terms 'not at all' and 'extremely'. ${ }^{21,22}$ The gastrointestinal well-being profile includes ratings on the aspects of 'abdominal pain' (Do you experience any abdominal pain?), 'stomach rumbling' (Do you experience any rumbling noises in your stomach?), 'flatulence' (Do you experience any flatulence [generation of excessive gas]?)', 'abdominal bloating' (Do you experience any bloated [swollen] feeling in the abdomen?), 'acid reflux' (Do you experience any acid reflux [heartburn]?), 'nausea' (Do you experience nausea?), and 'urge to vomit' (Do you experience an urge to vomit?), again anchored by the terms 'not at all' and 'extremely' measured as described previously. ${ }^{23}$

\subsection{Calculations and statistical analysis}

A sample size of 16 subjects was deemed sufficient to provide $>80 \%$ power to detect any significant differences of the main effect on blood glucose by employing a Hotelling-Lawley Trace statistical test and considering a type I error of 0.05 (2-tailed). ${ }^{24,25}$ All data obtained in this study are presented as least square means (LSMs) \pm standard errors of the mean (SEM) and for participant's baseline characteristics as means \pm SEM. SAS version 9.4 (SAS Institute Inc., Cary, NC, USA) was used for data analysis. Estimated metabolic clearance rate of glucose $\left(\mathrm{MCR}_{\mathrm{est}}\right)$ and estimated insulin sensitivity index ( $\left.\mathrm{ISI}_{\mathrm{est}}\right)$ were used as a measure of insulin sensitivity. ${ }^{26}$ In addition, insulinogenic index (IGI), estimated first phase (FP-IS est ), and

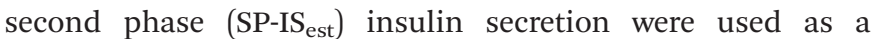
measure of $\beta$-cell function. ${ }^{26}$ Incremental peaks (iPeak) for b-glucose and s-insulin for BPB or control on each subject were calculated as the maximum postprandial increase from the baseline. Likewise, the incremental areas under the curve (iAUC) was calculated for BPB or control for each subject using the trapezoid model. ${ }^{27}$ The net area under the curve (netAUC) was calculated as a net value, considering both negative iAUC and positive iAUC. The main effects of time, treatment and their interaction on dependent variables including blood glucose, insulin, PYY, GLP-1, T3, T4, subjective appetite ratings and gastrointestinal well-being, as well as differences between the products at different time points were evaluated using mixed model analysis of covariance (ANCOVA, PROC MIXED procedure, SAS Institute) with repeated measures and an autoregressive covariance structure, followed by TukeyKramer's post-hoc test. The Kenward-Roger correction was applied to reduce small sample bias. The fixed effects included in the model were the corresponding baselines (fasting values), treatment, visit, time, and time $\times$ treatment interaction. Subject was treated as random effect while time and visit were included in the repeated effects. Statistical significance was considered at a $p$-value $<0.05$ (two tailed). Principal component analysis (PCA) was performed to investi-

gate the relationships and contributions of the observed variables in the different treatments, and was visualized in a bi-plot showing both loading and score plots. PCA analysis and visualization were performed using FactoMineR, factoextra and ggplot2 packages within R-environment version 3.2.4. ${ }^{28,29}$ Missing data was imputed using missMDA package. $^{30}$

\section{Results}

\subsection{Participant baseline characteristics}

Following an introductory meeting and screening, 16 subjects were eligible for the study. During the study, five subjects withdrew due to cannulation difficulties or other commitments. Thus, recruitment of five new participants was carried out during the study to assure that 16 subjects have completed the study. Baseline characteristics of the 16 subjects who completed the study are shown in Table 1.

\subsection{Polyphenolic compounds in BPB beverage}

The careful analysis of the separated compounds, using the information provided by the DAD detector as well as the MS detector coupled in series, together with the information that could be found in the literature and the MS database (FOOD DB) allowed the tentative identification of nine phenolic compounds and a diterpene lactone in BPB (Table 2). In fact, by combining the information of their MS spectra and $\mathrm{MS}^{\mathrm{E}}$ fragmentation patterns, it was possible to significantly increase the certainty of the tentative assignments. As shown in Fig. 2C and in Table 2, almost all the main peaks separated in UHPLC-DAD-ESI-QTOF-MS analysis could be tentatively identified. To our knowledge, this is the first time that these phenolic compounds have been described in black pepper.

\subsection{Glucose, insulin, insulin sensitivity and $\beta$-cell function}

Postprandial blood glucose and serum insulin over $3 \mathrm{~h}$ after consumption of BPB or control beverage are shown in Fig. 3A

Table 1 Anthropometric and biochemical characteristics of participants at screening visit

Variable

Subject, $n$ Age, years Weight, kg Height, m BMI, $\mathrm{kg} \mathrm{m}^{-2}$ BMR, kcal Fat, \% Ferritin $^{a}$, $\mu \mathrm{g} \mathrm{L}^{-1}$

Hemoglobin $^{b}, \quad 144.5 \pm 3.4$ (men: $150.8 \pm 2.9$; women: $134 \pm 5.4$ ) $\mathrm{g} \mathrm{L}^{-1}$

${ }^{a}$ Cut-off/normal range of ferritin for woman (13-148 $\left.\mu \mathrm{g} \mathrm{L}^{-1}\right)$ and men (27-365 $\left.\mu \mathrm{g} \mathrm{L}^{-1}\right)$. ${ }^{b}$ Cut-off/normal range of hemoglobin for woman (117-153 $\left.\mathrm{g} \mathrm{L}^{-1}\right)$ and men $\left(134-170 \mathrm{~g} \mathrm{~L}^{-1}\right)$. 
Table 2 Characterization (UV-Vis and MS characteristics, molecular formula (MF) and mass precision (mDa)) of phenolic compounds from BPB

\begin{tabular}{|c|c|c|c|c|c|c|}
\hline ID & $\begin{array}{l}\mathrm{RT} \\
(\mathrm{min})\end{array}$ & Compounds identified & $\begin{array}{l}\mathrm{UV}-\mathrm{Vis} \\
\text { maxima }(\mathrm{nm})\end{array}$ & {$[\mathrm{M}-\mathrm{H}]^{-}, \mathrm{MF}, \mathrm{mDa}$} & Main fragments detected & Ref. \\
\hline 1 & 4.70 & $\begin{array}{l}\text { Dihydroxybenzoic acid } \\
\text { hexoside-pentoside }\end{array}$ & $230.8,275.8,310.4$ & $447.1139, \mathrm{C}_{18} \mathrm{H}_{23} \mathrm{O}_{13}, 0.0$ & $152.0151,108.0163$ & 42 \\
\hline 2 & 5.30 & Decaffeoyl-acteoside & 228.8 & $461.1653, \mathrm{C}_{20} \mathrm{H}_{29} \mathrm{O}_{12},-0.6$ & $\begin{array}{l}315.1653,298.0974,165.0699 \\
135.0401\end{array}$ & 43 and 52 \\
\hline 3 & 5.74 & Cynaroside A & $229.8,265.81$ & $443.1884, \mathrm{C}_{21} \mathrm{H}_{31} \mathrm{O}_{10},-3,3$ & $375.0570,236.5559$ & 43 \\
\hline 4 & 7.30 & Apigenin 6,8-di-C-hexoside & $229.8,269.8,329.8$ & $593.1503, \mathrm{C}_{27} \mathrm{H}_{29} \mathrm{O}_{15},-0.3$ & $\begin{array}{l}575.1471,503.1240,473.1147, \\
383.0761,353.0690,325.0683, \\
297.0753\end{array}$ & 43 and 44 \\
\hline 5 & 8.24 & $\begin{array}{l}\text { Luteolin 6-C-hexoside- } \\
\text { 8-C-rhamnoside }\end{array}$ & $229.8,269.8,329.8$ & $593.1553, \mathrm{C}_{27} \mathrm{H}_{29} \mathrm{O}_{15}, 1.1$ & $\begin{array}{l}473.1058,429.0855,357.0617 \\
327.0517,309.0399,285.0388, \\
284.0329\end{array}$ & 43 and 44 \\
\hline 6 & 8.55 & $\begin{array}{l}\text { Apigenin 8-C-hexoside- } \\
\text { C-deoxyhexoside }\end{array}$ & $229.8,267.8,331.8$ & $577.1540, \mathrm{C}_{27} \mathrm{H}_{29} \mathrm{O}_{14},-1.7$ & $\begin{array}{l}\text { 457.1078, 413.0857, 311.0534, } \\
293.0448,283.0529,175.0001 \text {, } \\
117.0317\end{array}$ & $42-45$ \\
\hline 7 & 10.01 & $\begin{array}{l}\text { Kaempferol 3-rhamnoside-4'- } \\
\text { xyloside }\end{array}$ & $229.8,349.8$ & $563.1402, \mathrm{C}_{26} \mathrm{H}_{27} \mathrm{O}_{14}, 0.1$ & $417.0728,285.0423$ & 43 \\
\hline 8 & 10.20 & Apigenin 7-neohesperidoside & $266.8,338.8$ & $577.1540, \mathrm{C}_{27} \mathrm{H}_{29} \mathrm{O}_{14},-1.7$ & 269.0434 & 43 \\
\hline 9 & 10.88 & $\begin{array}{l}\text { Apigenin 8-C-arabinopyranoside-2"- } \\
\text { rhamnoside }\end{array}$ & $266.8,338.8$ & $547.1443, \mathrm{C}_{26} \mathrm{H}_{27} \mathrm{O}_{13},-0.9$ & 269.0434 & - \\
\hline
\end{tabular}
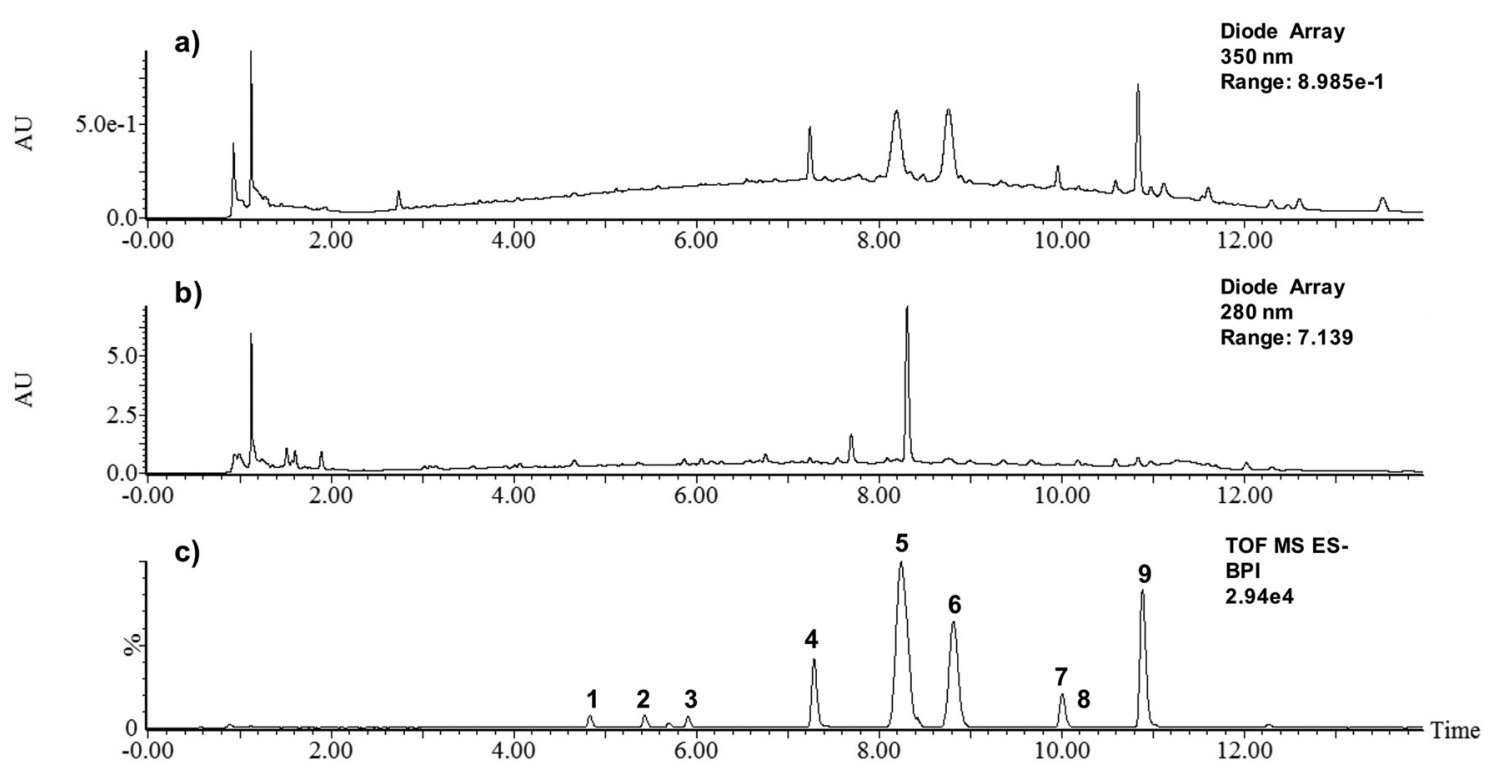

Fig. 2 Chromatograms corresponding to the UHPLC-DAD-ESI-QTOF-MS analysis of black pepper-based beverage at (a) $350 \mathrm{~nm}$; (b) $280 \mathrm{~nm}$ and (c) MS chromatogram obtained negative mode (base peak intensity).

and $\mathrm{B}$, respectively. Baseline concentrations of glucose and insulin did not differ between the two treatments $(P>0.05)$. The consumption of WWB challenge resulted in an increase of blood glucose, peaking at $45 \mathrm{~min}$ and returning to the baseline between 150-180 min. Although there was a $-17.5 \%$ and $-16.2 \%$ reduction of blood glucose $\mathrm{iAUC}_{0-180}$ and iPeak, respectively, after the BPB compared to the control beverage, no significant differences were observed. There was a tendency $\left(P=0.07\right.$; Table 3 ) for insulin iAUC $_{0-30}$ to be $-18.3 \%$ lower after the BPB ingestion compared to the control beverage. No significant differences were found for insulin sensitivity $\left(\mathrm{ISI}_{\mathrm{est}}\right.$ and $\mathrm{MCR}_{\mathrm{est}}$ ) or $\beta$-cell function (IGI, FP-IS ${ }_{\mathrm{est}}$, and
SP-IP $\left.{ }_{\text {est }}\right)$ between the BPB and the control beverage $(P>0.05$; Table 3).

\subsection{Subjective appetite ratings}

There were significant main effects of time $(P<0.0001)$ and treatment $(P<0.01)$, but no time $\times$ treatment interactions $(P>$ 0.05 ; Fig. 4) for all five appetite ratings. BPB significantly lowered 'hunger' ( $P=0.0007)$, 'desire to eat' $(P=0.0012)$ and 'prospective consumption' $(P=0.0011)$ compared to the control beverage. In addition, 'satiety' $(P=0.0044)$ and 'fullness' $(P=0.0009)$ were significantly increased after BPB, compared to the control beverage. 

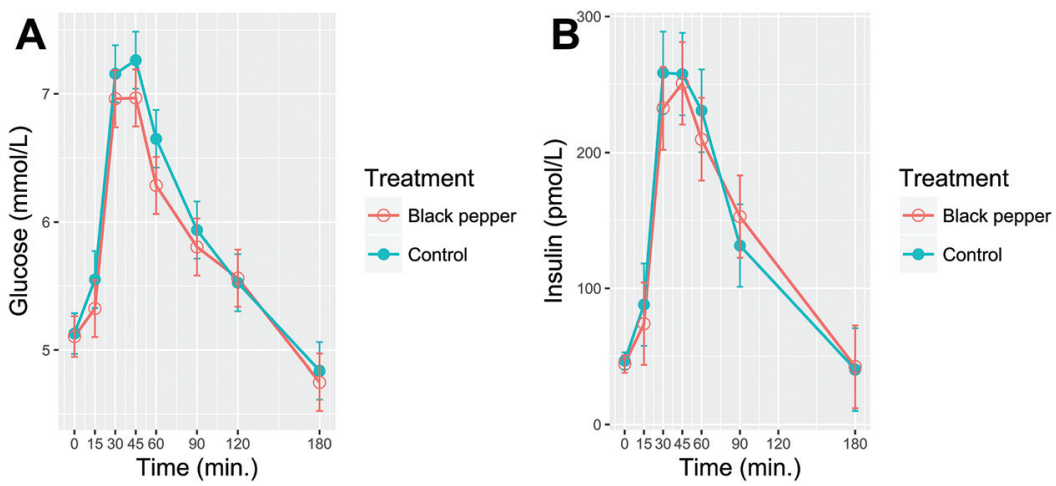

Fig. 3 LSM (least-square means) \pm SEM postprandial blood glucose (A) and insulin (B) responses after either the black pepper based beverage (BPB) or the control beverage, followed by the white wheat bread (WWB) challenge $(n=16)$. The mixed model analysis of covariance (ANCOVA, PROC MIXED procedure, SAS Institute) was employed to evaluate time, treatment, time $\times$ treatment interaction effects. (A) Glucose response: time effect, $P$ $<0.0001$; treatment effect, $P=0.09$; time $\times$ treatment interaction, $P=0.97$. (B) Insulin response: time effect, $P<0.0001$; treatment effect, $P=0.66$; time $\times$ treatment interaction, $P=0.56$.

Table 3 Metabolic parameters after intake of the test products ${ }^{a}$

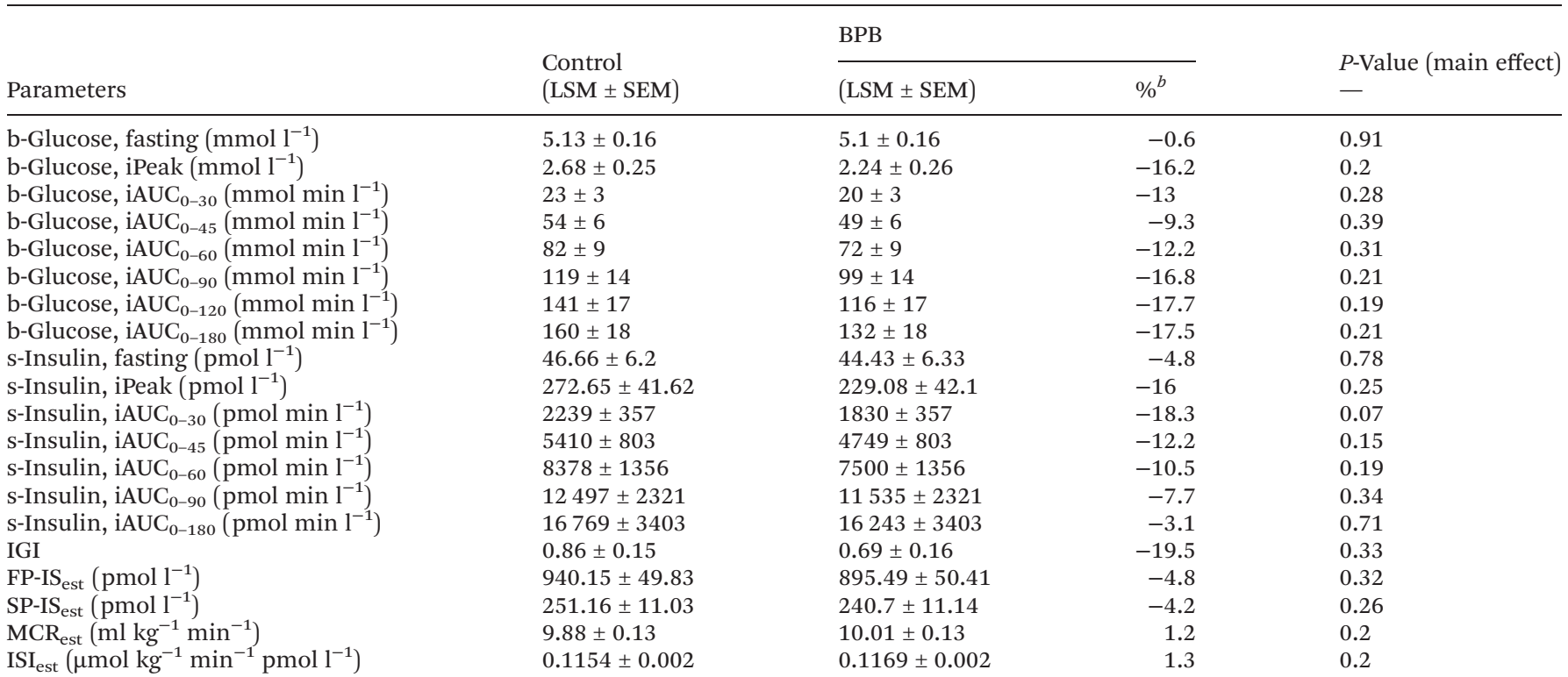

${ }^{a}$ Values are least squares means (LSM) $\pm \mathrm{SEM}, n=16 .{ }^{b}$ Indicate percentage difference in means concentration compared with control as reference (mixed-model ANCOVA followed by Tukey-Kramer's post-hoc test).

\subsection{Gastroinstestinal well-being}

A radar chart for the average value of each perceived gastrointestinal well-being aspect is shown in Fig. 5. Baseline gastrointestinal well-being profile were similar among the treatments $(P>0.05)$. No effect of treatment $(P>0.05)$, time $(P>0.05)$ and time $\times$ treatment interaction $(P>0.05)$ were observed for the seven aspects of gastrointestinal well-being.

\subsection{PYY and GLP-1}

Delta postprandial plasma PYY and GLP-1 after consumption of BPB or control beverage are shown in Fig. 6A and B, respectively. Baseline values for both PYY and GLP-1 were similar $(P>$ 0.05). The plasma GLP-1 peaked at min 30 for both BPB (43.08 $\pm 1.74 \mathrm{pM})$ and control beverage $(40.63 \pm 1.71 \mathrm{pM})$, then declined in $\min 60$. There were no time $(P=0.075)$, treatment $(P=0.98)$ nor time $\times$ treatment interaction $(P=0.77)$ effects for PYY. Only time $(P<0.0001)$, but no treatment $(P=0.19)$ or time $\times$ treatment interaction $(P=0.64)$ effects were observed for GLP-1.

\subsection{Triiodothyronine (T3) and thyroxine (T4)}

Delta postprandial T3 and T4 after consumption of BPB or the control beverage are shown in Fig. 7A and B, respectively. No difference $(P>0.05)$ was observed for baseline values of plasma T3 and T4 between the treatments. The plasma T3 slightly increased after $\mathrm{BPB}$, peaking at $30 \mathrm{~min}(1.76 \pm$ 

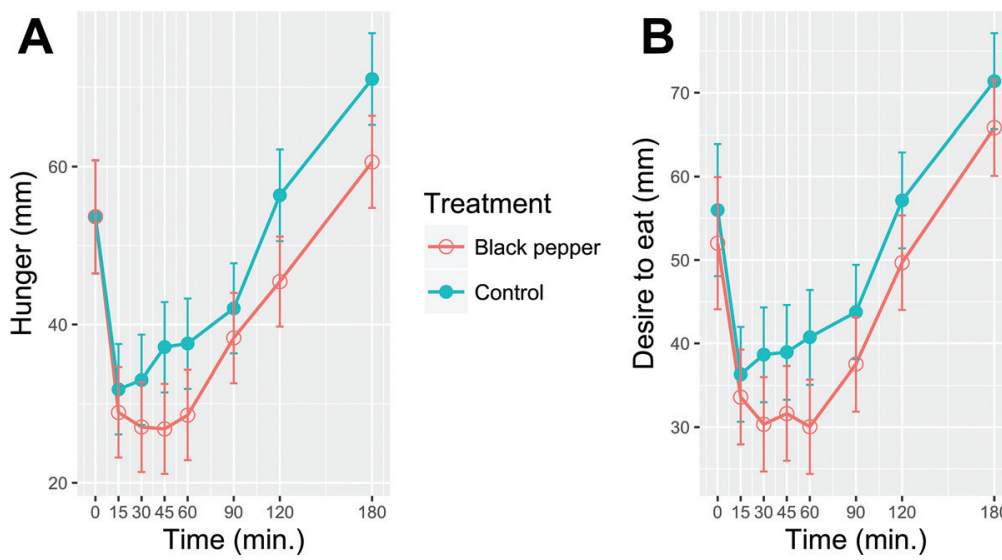

\section{Treatment \\ $\multimap$ Black pepper \\ $\rightarrow$ Control}
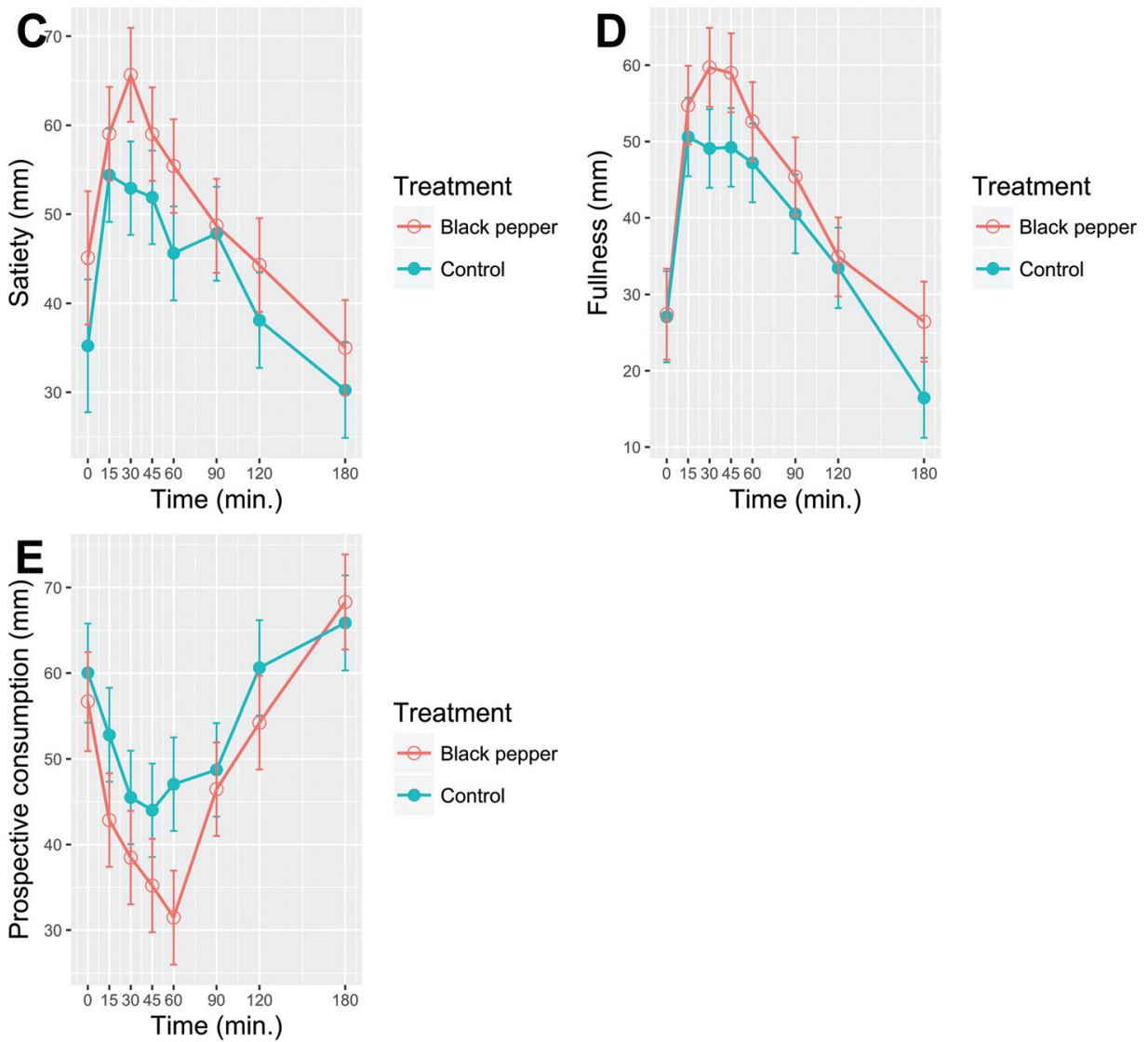

Fig. 4 Postprandial subjective appetite response in 'hunger' (A), 'desire to eat' (B), 'satiety' (C), 'fullness' (D) and 'prospective consumption' (E) after either the black pepper based beverage (BPB) or the control beverage, followed by the white wheat bread $(W W B)$ challenge $(n=16)$. The mixed model analysis of covariance (ANCOVA, PROC MIXED procedure, SAS Institute) was employed to evaluate time, treatment, time $\times$ treatment interaction effects. (A) 'Hunger' response: time effect, $P<0.0001$; treatment effect, $P=0.0007$; time $\times$ treatment interaction, $P=0.92$. (B) 'Desire to eat' response: time effect, $P<0.0001$; treatment effect, $P=0.001$; time $\times$ treatment interaction, $P=0.98$. (C) 'Satiety' response: time effect, $P<0.0001$; treatment effect, $P=0.004$; time $\times$ treatment interaction, $P=0.83$. (D) 'Fullness' response: time effect, $P<0.0001$; treatment effect, $P=0.0009$; time $\times$ treatment interaction, $P=0.84$. (E) 'Prospective consumption' response: time effect, $P<0.0001$; treatment effect, $P=0.001$; time $\times$ treatment interaction, $P=0.35$.

$0.024 \mathrm{nmol} \mathrm{L}^{-1}$ ), then decreased at min 60 and maintained a steady level until 3 hours for both BPB $\left(1.72 \pm 0.024 \mathrm{nmol} \mathrm{L}^{-1}\right)$ and the control beverage $\left(1.68 \pm 0.024 \mathrm{nmol} \mathrm{L}^{-1}\right)$. A time effect $(P<0.0001)$ but no main effects were observed for T3 (treatment $P=0.31$; time $\times$ treatment interaction $P=0.82)$ or T4 (time $P=0.12$; treatment $P=0.46$; time $\times$ treatment interaction
$P=0.51)$. Similar results were observed for the $\mathrm{T} 4: \mathrm{T} 3$ ratio (data not shown).

\subsection{Multivariate analysis}

The bi-plot in Fig. 8 captures $53.3 \%$ of the total variance explained $(31.6 \%$ by first dimension/principal component 1 


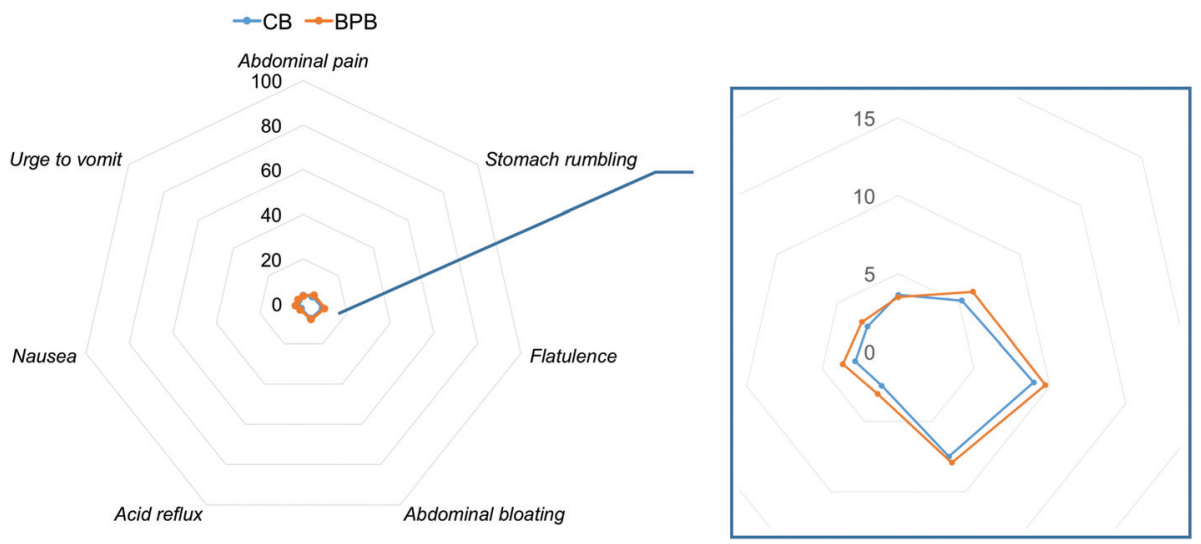

Fig. 5 Radar chart of average gastrointestinal well-being aspect including 'abdominal pain', 'stomach rumbling', 'flatulence', 'abdominal bloating', 'acid reflux', 'nausea' and 'urge to vomit' after either the black pepper based beverage (BPB) or the control beverage, followed by the white wheat bread (WWB) challenge $(n=16)$.
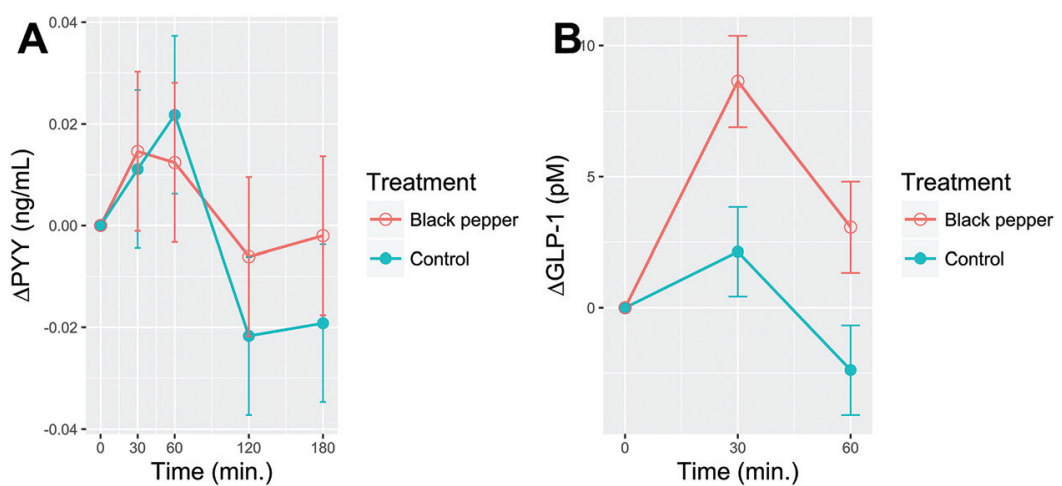

Fig. 6 Delta LSM (least-square means) \pm SEM of postprandial plasma peptide tyrosine-tyrosine/PYY (A, $n=16)$ and glucagon-like peptide-1/GLP-1 (B, $n=14$ due to sample loss) after either the black pepper based beverage (BPB) or the control beverage, followed by the white wheat bread (WWB) challenge. The mixed model analysis of covariance (ANCOVA, PROC MIXED procedure, SAS Institute) was employed to evaluate time, treatment, time $\times$ treatment interaction effects. (A) $\triangle \mathrm{PYY}$ response: time effect, $P=0.075$; treatment effect, $P=0.98$; time $\times$ treatment interaction, $P=0.77$. (B) $\Delta$ GLP-1 response: time effect, $P<0.0001$; treatment effect, $P=0.198$; time $\times$ treatment interaction, $P=0.64$.
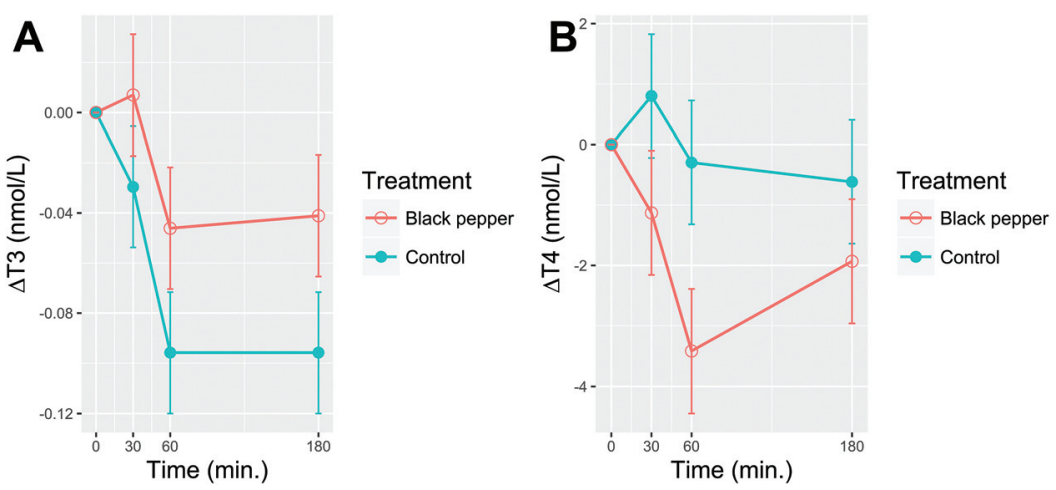

Fig. 7 Postprandial triiodothyronine/T3 (A) and thyroxine/T4 (B) after either the black pepper based beverage (BPB) or the control beverage, followed by the white wheat bread (WWB) challenge $(n=16)$. The mixed model analysis of covariance (ANCOVA, PROC MIXED procedure, SAS Institute) was employed to evaluate time, treatment, time $\times$ treatment interaction effects. (A) $\triangle T$ T response: time effect, $P<0.0001$; treatment effect, $P=$ 0.31; time $\times$ treatment interaction, $P=0.82$. (B) $\Delta \mathrm{T} 4$ response: time effect, $P=0.12$; treatment effect, $P=0.46$; time $\times$ treatment interaction, $P=$ 0.51 . 


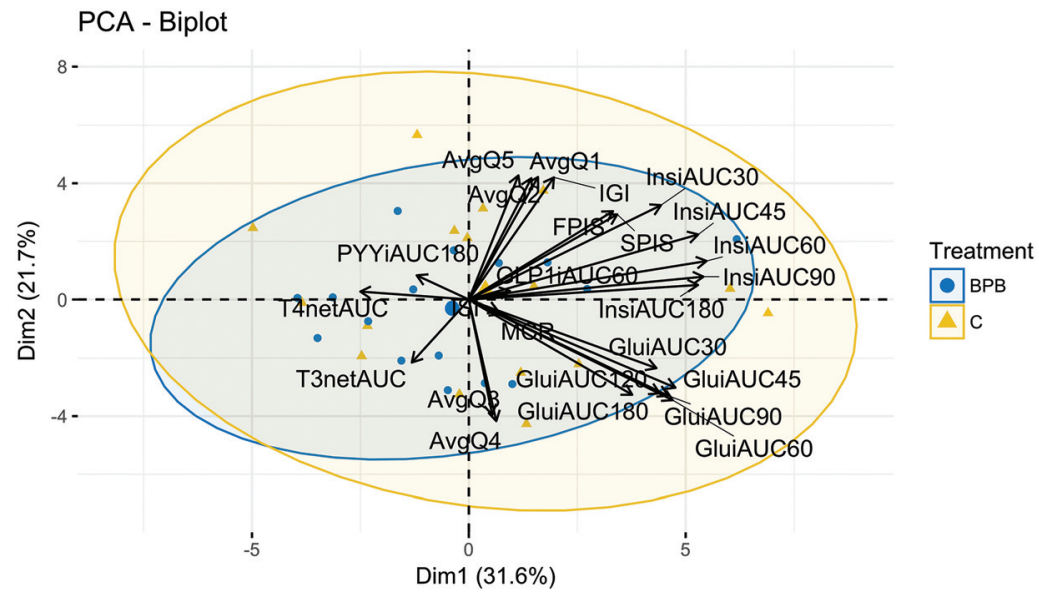

Fig. 8 Principal component analysis bi-plot based on the tested physiological parameters after treatments. AvgQ1, average 'hunger'; AvgQ2, average 'desire to eat'; AvgQ3, average 'satiety'; AvgQ4, average 'fullness'; AvgQ5, average 'prospective consumption'; FPIS, estimated first phase insulin secretion; GluiAUC, incremental area under the curve of glucose; GLP1iAUC, incremental area under the curve of glucagon-like peptide 1; IGI, insulinogenic index; InsiAUC, incremental area under the curve of insulin; ISI, insulin sensitivity index; PYYiAUC, incremental area under the curve of peptide tyrosine-tyrosine; MCR, estimated metabolic clearance rate; SPIS, estimated second phase insulin secretion; T3netAUC, net area under the curve of triiodothyronine; T4netAUC, net area under the curve of thyroxine.

(PC1) and $21.7 \%$ by the second dimension PC2). In fact, the proportion of variance explained by components which have eigenvalues $>1$ covers up to PC6, with $87.54 \%$ of total variance explained. The loading plot in bi-plot showed that 'hunger', 'desire to eat' and 'prospective consumption' were positively cor-

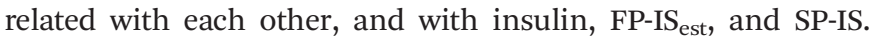
These parameters were all negatively correlated with T3. The perceived 'hunger', 'desire to eat' and 'prospective consumption' had no association with glucose. In contrast, T4 was negatively correlated with glucose, as shown on the factor map.

\section{Discussion}

To our knowledge, this is the first study to examine a BPB preload on postprandial glucose metabolism, subjective appetite, gastrointestinal well-being, gut (PYY and GLP-1), and thyroid (T3 and T4) hormones. The main findings of our study are that consumption of the BPB preload modulated postprandial appetite response by increasing 'satiety' and 'fullness', while reducing 'hunger', 'desire to eat' and 'prospective consumption' when consumed shortly before a WWB meal challenge. Thyroid function might be implicated after a postprandial meal challenge. However, the extent of this observation and the relationship between thyroid hormones and energy regulation deserves further investigation.

No significant differences in blood glucose regulation, despite a tendency for reduced early insulin release at $30 \mathrm{~min}$ $(-18 \%, P=0.07)$, was found between the BPB and the control beverage. A similar trend was observed in a previous study showing that $1.5 \mathrm{~g}$ black pepper consumed together with a mixed-meal elicited $-12 \%$ less insulin compared to a control, but it was not statistically significant. ${ }^{31}$ However, a similar study with other pungent spices, such as red pepper consump- tion for longer term (4-weeks) attenuated postprandial hyperinsulinaemia. $^{32}$ Since there is no longer-term intake data on black pepper, we can only speculate that black pepper might modulate glucose/insulin after long-term habitual consumption. This is supported by an animal study showing that piperine administration (20 $\mathrm{mg} \mathrm{kg} \mathrm{kg}^{-1}$ ) for 14-days reduced blood glucose level by $-19 \%$ compared to the control. ${ }^{33}$

The present results showed that BPB preload reduced 'hunger' $(-17 \%, P=0.0007)$, 'desire to eat' $(-15 \%, P=0.001)$, 'prospective consumption' $(-17 \%, P=0.001)$ and increased 'satiety' (14\%, $P=0.004)$ and 'fullness' (16\%, $P=0.0009)$ compared to the control beverage. The current results on appetite diverge from a previous study that examined incorporation of $1.5 \mathrm{~g}$ black pepper into a mixed-meal diet on postprandial appetite response in normal-weight male subjects. ${ }^{34}$ In addition to differences in study design between the two studies, the mixed standard meal was composed of foods varying in macronutrient content (bread, ham, butter and scrambled eggs) and included other phenolic-contained foods (raspberry jam, stewed apples, shredded beetroot and multifruit juice), which were substantially different from the WWB challenge meal offered in the present study. WesterterpPlantenga et al. showed that both oral exposure and capsuleform intervention of capsaicin induced perceived satiety and reduced daily energy intake over two days, relative to a control. ${ }^{35}$ The reduction in appetite after capsaicin intake was observed only after oral exposure and could thus be associated to perceived spiciness. ${ }^{35}$ However, our results on gastrointestinal well-being are discordant with a previous study by van Avesaat et al. on pungent spices using capsaicin as a regiment. ${ }^{36}$ Their study showed that intra-duodenal capsaicin delivery affects satiety and gastrointestinal stress while it had no impact on postprandial PYY and GLP-1 release. ${ }^{36}$ Thus, they inferred that the satiety-inducing mechanism of capsaicin 
may not be related to gut hormone secretion but to the perceived spiciness and gastrointestinal stress. ${ }^{36}$ We instead showed that neither the BPB nor the control beverage affected 'abdominal pain', 'stomach rumbling', 'flatulence', 'abdominal bloating', 'acid reflux', 'nausea' and 'urge to vomit' ratings. In line with the present study, we showed that overall appetite was significantly reduced after BPB intake and although BPB exhibited 23\% higher GLP-1 concentrations (control: $7 \%$ ) at 30 min compared to baseline, no statistical difference was observed. Likewise, no difference in PYY was observed after BPB compared to the control beverage. Therefore, our results showed that perceived satiety was not coherent with gut hormone or gastrointestinal well-being responses. As depicted in the factor map/bi-plot (Fig. 8), the contribution of gut hormones PYY and GLP-1 to the variance explained is rather small. In addition, the position of gut hormones is close to perpendicular to 'hunger', 'desire to eat' and 'prospective consumption' which implicates no observed correlation among those factors. Previously, O'Connor et al. performed a study showing that inclusion of black pepper in the diet did not modify $24 \mathrm{~h}$ energy expenditure, glucose and insulin responses or gut hormone (GLP-1, PYY, GIP and ghrelin) levels in overweight postmenopausal women. ${ }^{31}$ However, gut hormones were only measured at $30 \mathrm{~min}$ post challenge and no appetite ratings were recorded, which makes comparisons to the present study difficult.

There are various mechanisms to explain the greater effect on satiety and tendency to lower glucose levels by an acute BPB preload compared to the control beverage. It has been suggested that these effects are due to bioactive compounds contained in black pepper, such as piperine, isopiperine, isochavicine, piperanine, piperolein $\mathrm{A}$ and piperolein $\mathrm{B}$, which might act on transient receptor potential cation channel subfamily V member 1 (TRPV1). ${ }^{37,38}$ TRPV1 is widely found in the oral cavity and its activation is well-known to enhance energy metabolism, improve glucose homeostasis as well as potentially affect appetite responses. ${ }^{39,40}$ However, piperine and its derivatives were not found in our intervention beverage due to its low water solubility and melting point (about 128 to $\left.130{ }^{\circ} \mathrm{C}\right) .{ }^{41}$ Consequently, our short extraction time ( $\left.3 \mathrm{~min}\right)$ and water temperature of $90{ }^{\circ} \mathrm{C}$ may not have been adequate to extract compounds like piperine. Therefore, other polyphenolic compounds such as apigenin, luteolin, kaempferol and their derivatives might have modulated the effects in our study. Apigenin and its derivatives, which together belong to flavones, were tentatively identified in peak 4 (apigenin 6,8-diC-hexoside, known as vicenin 2 isomer), peak 6 (apigenin 8-Chexoside-C-deoxyhexoside), peak 8 (apigenin 7-neohesperidoside, known as rhoifolin) and peak 9 (apigenin 8-C-arabinopyranoside-2"-rhamnoside), respectively. Their experimental masses are in agreement with their theoretical masses and MS/MS fragmentation patterns reported in the FooDB database, the predicted MS/MS spectra obtained in CFM-ID (http:// cfmid.wishartlab.com) and the literature. ${ }^{42-45}$ Recent reports have shown that C-glycosylation in apigenin have potent antidiabetic, anti-Alzheimer's disease and anti-inflammatory activities. ${ }^{46}$ Interestingly, one in vivo study showed that apigenin intervention affects both short- and long-terms food intake. ${ }^{47}$ In addition, a 30 days intervention with apigenin was shown to reduce body weight gain in $\mathrm{C} 57 \mathrm{BL} / 6$ mice. $^{47}$ Moreover, apigenin and its derivatives are found abundantly in fenugreek (Trigonella foenum-graecum) seeds. ${ }^{48}$ It has been shown that fenugreek could lower both postprandial glucose and appetite responses in overweight/obese subjects. ${ }^{49,50}$ Furthermore, the chemosensory properties and oral heat/ burning of pungent spices per se might have implications for perceived satiety after intake. To evaluate such effects, an interesting approach with a slightly different study design was performed by Andersen et al. ${ }^{51}$ They evaluated the effect of equally liked soup (spicy soup enriched with cayenne pepper and non-spicy soup) on perceived appetite, sensory specific desires and well-being. Instead of giving one preload to be consumed at once, the soup was served into small portions ( $75 \mathrm{~g})$ and was consumed every 5 min during 1 hour. Immediately after each small portion, perceived appetite was measured, while measurement of well-being was extended up to $5 \mathrm{~h}$. Their results showed that spicy soup enriched with cayenne pepper induced higher satiety and sensory satisfaction during and 1 hour after consumption. ${ }^{51}$

Another interesting compound found in BPB was dihydroxybenzoic acid hexoside-pentoside which belong to the phenolic acids. The tentatively identified dihydroxybenzoic acid hexoside-pentoside (peak 1) has previously been described in Ammar et al. ${ }^{42}$ This peak presented a molecular ion at $\mathrm{m} / \mathrm{z}$ $447.1139[\mathrm{M}-\mathrm{H}]^{-}$. The second eluted compound tentatively identified as decaffeoyl-acteoside or verbasoside has a molecular ion at $m / z 461.1653[\mathrm{M}-\mathrm{H}]^{-}$. The $\mathrm{MS}^{\mathrm{E}}$ fragmentation produced ions at $\mathrm{m} / \mathrm{z} 315$ and 298 corresponding to the loss of a rhamnose and hexose unit, respectively. Among other compounds, verbasoside was found in lemon verbena which is associated with anti-inflammatory properties and has traditionally been used to treat gastrointestinal disorders. ${ }^{52}$ The third eluted compound was tentatively assigned as cynaroside A (peak 3) which is commonly found in herbs and spices. ${ }^{43}$ Luteolin 6-C-hexoside-8-C-rhamnoside appears on peak 5 with molecular ion at $m / z 593.1553[\mathrm{M}-\mathrm{H}]^{-}$. The tentatively identified kaempferol 3-rhamnoside-4'-xyloside which belongs to the flavonols was eluted at peak 7 with a molecular ion at $\mathrm{m} / \mathrm{z}$ $563.1402[\mathrm{M}-\mathrm{H}]^{-}$. The experimental masses of peak 5 and peak 7 are in agreement with the theoretical masses of luteolin 6-C-hexoside-8-C-rhamnoside and kaempferol 3-rhamnoside4 '-xyloside and MS/MS fragmentation patterns which have been reported in the FooDB database, the predicted MS/MS spectra obtained from CFM-ID (http://cfmid.wishartlab.com) and the literature. ${ }^{42,44}$

Thyroid hormones are known for their role as regulators of energy balance and metabolism in the peripheral and central systems ${ }^{53}$ and were chosen as exploratory markers in this study. Previously, oral and intravenous glucose loads induced $\mathrm{T} 4$ reduction and slightly increased $\mathrm{T} 3$-levels postprandially in overweight children. ${ }^{54}$ Conversely, a hypocaloric intervention (600-1000 kcal per day) for 21 days reduced T3 while increas- 
ing T4 concentrations after an oral glucose load. ${ }^{54}$ In the current study we showed that a WWB meal challenge containing $50 \mathrm{~g}$ available $\mathrm{CHO}$, irrespective of BPB consumption, could potentially affect postprandial thyroid hormones in healthy subjects. While the effect of BPB on T3 was observed as a time effect, the multivariate analysis showed that subjects with BPB (indicated as a blue dot; Fig. 8) clustered in the lower leftside and were highly associated with higher T3. In addition, glucose had a negative correlation with T4. However, no firm conclusion can be drawn from this exploratory observation and further investigations are needed. Interestingly, one study showed that piperine intervention in a high fat diet (HFD)-fed mice increased both T3 and T4 compared to a HFD-fed alone. ${ }^{55}$ We speculate that the lack of statistical significance for treatment in our study might be due to the relatively low concentration of bioactive compounds contained in our BPB regiment (20 mg GAE), while in the animal study a piperine dose of $40 \mathrm{mg}$ per $\mathrm{kg}$ body weight was used. ${ }^{55}$ In addition, our study was designed for the post-prandial phase while the animal study performed previously was conducted in a long-term setting.

We would like to acknowledge some limitations in our study. No measures of perceived palatability of the BPB were taken and this may have influenced the appetite ratings. However, the effect of palatability and sensory properties on satiety remains a subject of discussion. De Graaf et al. showed that palatability of the beverage or food influences satiation (meal termination) more than satiety (factors that influence the time interval between meals). ${ }^{56}$ Thus, even if the BPB differed in flavor, that would most likely have had an impact primarily on satiation. Furthermore, we did not measure ad libitum energy intake at the subsequent meal, which could have shown if the actual intake was affected by our regimen. Further experiments in obese or pre-diabetic/diabetic subjects are necessary to draw a bigger picture on the effects of black pepper on glycaemia, appetite and energy balance.

Overall, we conclude that BPB appears to have the potential to modulate perceived appetite by lowering 'hunger', 'desire to eat' and 'prospective consumption' and increasing 'satiety' and 'fullness' without affecting gastrointestinal well-being. Further experiments are needed to establish the relevant dose and mode of intake to optimize the effects. This work adds to the limited research investigating the effects of spices, particularly pungent spices like black pepper, on appetite regulation.

\section{Author contributions}

Y.C.Z., E.Ö. conceived and designed the experiments; Y.C.Z. wrote the clinical experiment protocol for ethical submission; Y.C.Z. led and conducted the experiment as well as responsible for clinical trials data acquisition; M.P. performed LC-MS experiment and data interpretation; Y.C.Z., E.Ö. performed the statistical analysis; Y.C.Z., M.P. drafted the initial manuscript; E.Ö., A.D. and C.T. supported in interpreting data and contributed to the manuscript. All authors read and approved the final manuscript.

\section{Abbreviations}

i/netAUC Incremental/net area under the curve

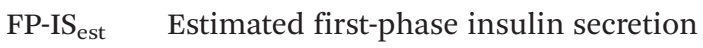

GAE Gallic acid equivalent

GLP-1 Glucagon-like peptide 1

b-glucose Blood glucose

IGI Insulinogenic index

$\mathrm{MCR}_{\text {est }} \quad$ Estimated metabolic clearance rate of glucose

ISI $_{\text {est }} \quad$ Estimated insulin sensitivity index

s-insulin Serum insulin

PYY Peptide tyrosine-tyrosine

SP-IS $_{\text {est }} \quad$ Estimated second-phase insulin secretion

T3 Triiodothyronine

T4 Thyroxine

VAS Visual analogue scale

WWB White wheat bread

\section{Conflicts of interest}

The authors have declared no conflict of interest.

\section{Acknowledgements}

The authors thank Santa Maria AB, Mölndal, Sweden for donation of the spices used in this study. Y. C. Z. thanks the Swedish Nutrition Foundation (SNF) for part of a research grant provided. M. P. thanks the Spanish Ministry of Economy and Competitiveness (MINECO) for Juan de la Cierva contract (IJCI-2014-22143). Funding for this study and publication were provided by Antidiabetic Food Centre, a VINNOVA VINN Excellence Centre at Lund University (Grant No. 2013/38).

\section{References}

1 M. Ng, T. Fleming, M. Robinson, B. Thomson, N. Graetz, C. Margono, E. C. Mullany, S. Biryukov, C. Abbafati, S. F. Abera, J. P. Abraham, N. M. Abu-Rmeileh, T. Achoki, F. S. AlBuhairan, Z. A. Alemu, R. Alfonso, M. K. Ali, R. Ali, N. A. Guzman, W. Ammar, P. Anwari, A. Banerjee, S. Barquera, S. Basu, D. A. Bennett, Z. Bhutta, J. Blore, N. Cabral, I. C. Nonato, J. C. Chang, R. Chowdhury, K. J. Courville, M. H. Criqui, D. K. Cundiff, K. C. Dabhadkar, L. Dandona, A. Davis, A. Dayama, S. D. Dharmaratne, E. L. Ding, A. M. Durrani, A. Esteghamati, F. Farzadfar, D. F. Fay, V. L. Feigin, A. Flaxman, M. H. Forouzanfar, A. Goto, M. A. Green, R. Gupta, N. Hafezi-Nejad, G. J. Hankey, H. C. Harewood, R. Havmoeller, S. Hay, L. Hernandez, A. Husseini, B. T. Idrisov, N. Ikeda, F. Islami, E. Jahangir, S. K. Jassal, S. H. Jee, M. Jeffreys, J. B. Jonas, E. K. Kabagambe, S. E. Khalifa, A. P. Kengne, Y. S. Khader, Y. H. Khang, D. Kim, R. W. Kimokoti, J. M. Kinge, Y. Kokubo, S. Kosen, G. Kwan, T. Lai, M. Leinsalu, Y. Li, X. Liang, S. Liu, G. Logroscino, 
P. A. Lotufo, Y. Lu, J. Ma, N. K. Mainoo, G. A. Mensah, T. R. Merriman, A. H. Mokdad, J. Moschandreas, M. Naghavi, A. Naheed, D. Nand, K. M. Narayan, E. L. Nelson, M. L. Neuhouser, M. I. Nisar, T. Ohkubo, S. O. Oti, A. Pedroza, D. Prabhakaran, N. Roy, U. Sampson, H. Seo, S. G. Sepanlou, K. Shibuya, R. Shiri, I. Shiue, G. M. Singh, J. A. Singh, V. Skirbekk, N. J. Stapelberg, L. Sturua, B. L. Sykes, M. Tobias, B. X. Tran, L. Trasande, H. Toyoshima, S. van de Vijver, T. J. Vasankari, J. L. Veerman, G. Velasquez-Melendez, V. V. Vlassov, S. E. Vollset, T. Vos, C. Wang, X. Wang, E. Weiderpass, A. Werdecker, J. L. Wright, Y. C. Yang, H. Yatsuya, J. Yoon, S. J. Yoon, Y. Zhao, M. Zhou, S. Zhu, A. D. Lopez, C. J. Murray and E. Gakidou, Global, regional, and national prevalence of overweight and obesity in children and adults during 1980-2013: a systematic analysis for the Global Burden of Disease Study 2013, Lancet, 2014, 384, 766-781.

2 D. Withrow and D. A. Alter, The economic burden of obesity worldwide: a systematic review of the direct costs of obesity, Obes. Rev., 2011, 12, 131-141.

3 M. Hopkins and J. E. Blundell, Energy balance, body composition, sedentariness and appetite regulation: pathways to obesity, Clin. Sci., 2016, 130, 1615-1628.

4 B. van Ommen, J. van der Greef, J. M. Ordovas and H. Daniel, Phenotypic flexibility as key factor in the human nutrition and health relationship, Genes Nutr., 2014, 9, 1-9.

5 M. J. Amiot, C. Riva and A. Vinet, Effects of dietary polyphenols on metabolic syndrome features in humans: a systematic review, Obes. Rev., 2016, 17, 573-586.

6 S. Coe and L. Ryan, Impact of polyphenol-rich sources on acute postprandial glycaemia: a systematic review, J. Nutr. Sci., 2016, 5, e24.

7 S. D. Ball, K. R. Keller, L. J. Moyer-Mileur, Y. W. Ding, D. Donaldson and W. D. Jackson, Prolongation of satiety after low versus moderately high glycemic index meals in obese adolescents, Pediatrics, 2003, 111, 488-494.

8 J. M. Warren, C. J. Henry and V. Simonite, Low glycemic index breakfasts and reduced food intake in preadolescent children, Pediatrics, 2003, 112, e414.

9 S. A. Tucci, Phytochemicals in the Control of Human Appetite and Body Weight, Pharmaceuticals, 2010, 3, 748-763.

10 W. S. da-Silva, J. W. Harney, B. W. Kim, J. Li, S. D. Bianco, A. Crescenzi, M. A. Christoffolete, S. A. Huang and A. C. Bianco, The small polyphenolic molecule kaempferol increases cellular energy expenditure and thyroid hormone activation, Diabetes, 2007, 56, 767-776.

11 S. Wang, N. Moustaid-Moussa, L. Chen, H. Mo, A. Shastri, R. Su, P. Bapat, I. Kwun and C. L. Shen, Novel insights of dietary polyphenols and obesity, J. Nutr. Biochem., 2014, 25, 1-18.

12 K. Srinivasan, Antioxidant potential of spices and their active constituents, Crit. Rev. Food Sci. Nutr., 2014, 54, 352-372.

13 H. Dressler and C. Smith, Food choice, eating behavior, and food liking differs between lean/normal and overweight/ obese, low-income women, Appetite, 2013, 65, 145-152.

14 M. J. Ludy, G. E. Moore and R. D. Mattes, The effects of capsaicin and capsiate on energy balance: critical review and meta-analyses of studies in humans, Chem. Senses, 2012, 37, 103-121.

15 S. Varghese, P. Kubatka, L. Rodrigo, K. Gazdikova, M. Caprnda, J. Fedotova, A. Zulli, P. Kruzliak and D. Busselberg, Chili pepper as a body weight-loss food, Int. J. Food Sci. Nutr., 2017, 68, 392-401.

16 M. Meghwal and T. K. Goswami, Piper nigrum and piperine: an update, Phytother. Res., 2013, 27, 1121-1130.

17 K. Srinivasan, Black pepper and its pungent principlepiperine: a review of diverse physiological effects, Crit. Rev. Food Sci. Nutr., 2007, 47, 735-748.

18 M. Westerterp-Plantenga, K. Diepvens, A. M. Joosen, S. Berube-Parent and A. Tremblay, Metabolic effects of spices, teas, and caffeine, Physiol. Behav., 2006, 89, 85-91.

19 D. M. Mudie, K. Murray, C. L. Hoad, S. E. Pritchard, M. C. Garnett, G. L. Amidon, P. A. Gowland, R. C. Spiller, G. E. Amidon and L. Marciani, Quantification of gastrointestinal liquid volumes and distribution following a $240 \mathrm{~mL}$ dose of water in the fasted state, Mol. Pharm., 2014, 11, 3039-3047.

20 V. L. Singleton, R. Orthofer and R. M. Lamuela-Raventós, in Methods in Enzymology, Academic Press, 1999, vol. 299, pp. 152-178.

21 A. Flint, A. Raben, J. E. Blundell and A. Astrup, Reproducibility, power and validity of visual analogue scales in assessment of appetite sensations in single test meal studies, Int. J. Obes. Relat. Metab. Disord., 2000, 24, 38-48.

22 D. M. Marsh-Richard, E. S. Hatzis, C. W. Mathias, N. Venditti and D. M. Dougherty, Adaptive Visual Analog Scales (AVAS): a modifiable software program for the creation, administration, and scoring of visual analog scales, Behav. Res. Methods, 2009, 41, 99-106.

23 H. J. Bovenschen, M. J. Janssen, M. G. van Oijen, R. J. Laheij, L. G. van Rossum and J. B. Jansen, Evaluation of a gastrointestinal symptoms questionnaire, Dig. Dis Sci., 2006, 51, 1509-1515.

24 S. M. Kreidler, K. E. Muller, G. K. Grunwald, B. M. Ringham, Z. T. Coker-Dukowitz, U. R. Sakhadeo, A. E. Baron and D. H. Glueck, GLIMMPSE: Online Power Computation for Linear Models with and without a Baseline Covariate, J. Stat. Softw., 2013, 54(10), i10.

25 A. Dougkas and E. Ostman, Protein-Enriched Liquid Preloads Varying in Macronutrient Content Modulate Appetite and Appetite-Regulating Hormones in Healthy Adults, J. Nutr., 2016, 146, 637-645.

26 M. Stumvoll, T. Van Haeften, A. Fritsche and J. Gerich, Oral glucose tolerance test indexes for insulin sensitivity and secretion based on various availabilities of sampling times, Diabetes Care, 2001, 24, 796-797.

27 F. Brouns, I. Bjorck, K. N. Frayn, A. L. Gibbs, V. Lang, G. Slama and T. M. Wolever, Glycaemic index methodology, Nutr. Res. Rev., 2005, 18, 145-171.

28 H. Wickham, ggplot2: Elegant Graphics for Data Analysis, Springer-Verlag New York, 2009.

29 S. Lê, J. Josse and F. Husson, FactoMineR: An R Package for Multivariate Analysis, J. Stat. Softw., 2008, 25, 18. 
30 J. Josse and F. Husson, missMDA: A Package for Handling Missing Values in Multivariate Data Analysis, J. Stat. Softw., 2016, 70, 31.

31 A. O’Connor, K. D. Corbin, D. C. Nieman and A. G. Swick, A randomized, controlled trial to assess short-term black pepper consumption on 24-hour energy expenditure and substrate utilization, Funct. Foods Health Dis., 2013, 3, 377-388.

32 K. D. Ahuja, I. K. Robertson, D. P. Geraghty and M. J. Ball, Effects of chili consumption on postprandial glucose, insulin, and energy metabolism, Am. J. Clin. Nutr., 2006, 84, 63-69.

33 S. Atal, R. P. Agrawal, S. Vyas, P. Phadnis and N. Rai, Evaluation of the effect of piperine per se on blood glucose level in alloxan-induced diabetic mice, Acta Pol. Pharm., 2012, 69, 965-969.

34 N. T. Gregersen, A. Belza, M. G. Jensen, C. Ritz, C. Bitz, O. Hels, E. Frandsen, D. J. Mela and A. Astrup, Acute effects of mustard, horseradish, black pepper and ginger on energy expenditure, appetite, ad libitum energy intake and energy balance in human subjects, Br. J. Nutr., 2013, 109, 556-563.

35 M. S. Westerterp-Plantenga, A. Smeets and M. P. Lejeune, Sensory and gastrointestinal satiety effects of capsaicin on food intake, Int. J. Obes., 2005, 29, 682-688.

36 M. van Avesaat, F. J. Troost, M. S. Westerterp-Plantenga, Z. Helyes, C. W. Le Roux, J. Dekker, A. A. Masclee and D. Keszthelyi, Capsaicin-induced satiety is associated with gastrointestinal distress but not with the release of satiety hormones, Am. J. Clin. Nutr., 2016, 103, 305-313.

37 Y. Okumura, M. Narukawa, Y. Iwasaki, A. Ishikawa, H. Matsuda, M. Yoshikawa and T. Watanabe, Activation of TRPV1 and TRPA1 by black pepper components, Biosci., Biotechnol., Biochem., 2010, 74, 1068-1072.

38 F. N. McNamara, A. Randall and M. J. Gunthorpe, Effects of piperine, the pungent component of black pepper, at the human vanilloid receptor (TRPV1), Br. J. Pharmacol., 2005, 144, 781-790.

39 P. Wang, Z. Yan, J. Zhong, J. Chen, Y. Ni, L. Li, L. Ma, Z. Zhao, D. Liu and Z. Zhu, Transient receptor potential vanilloid 1 activation enhances gut glucagon-like peptide- 1 secretion and improves glucose homeostasis, Diabetes, 2012, 61, 2155-2165.

40 Z. Luo, L. Ma, Z. Zhao, H. He, D. Yang, X. Feng, S. Ma, X. Chen, T. Zhu, T. Cao, D. Liu, B. Nilius, Y. Huang, Z. Yan and Z. Zhu, TRPV1 activation improves exercise endurance and energy metabolism through PGC-1alpha upregulation in mice, Cell Res., 2012, 22, 551-564.

41 L. Gorgani, M. Mohammadi, G. D. Najafpour and M. Nikzad, Piperine-the bioactive compound of black pepper: from isolation to medicinal formulations, Compr. Rev. Food Sci. Food Saf., 2017, 16, 124-140.

42 S. Ammar, M. del Mar Contreras, O. Belguith-Hadrich, A. Segura-Carretero and M. Bouaziz, Assessment of the distribution of phenolic compounds and contribution to the antioxidant activity in Tunisian fig leaves, fruits, skins and pulps using mass spectrometry-based analysis, Food Funct., 2015, 6, 3663-3677.
43 FooDB, available online: http://www.foodb.ca/(accessed on 7 March 2017).

44 A. Marin, F. Ferreres, F. A. Tomas-Barberan and M. I. Gil, Characterization and quantitation of antioxidant constituents of sweet pepper (Capsicum annuum L.), J. Agric. Food Chem., 2004, 52, 3861-3869.

45 R. M. Ibrahim, A. M. El-Halawany, D. O. Saleh, E. M. B. E. Naggar, A. E.-R. O. El-Shabrawy and S. S. El-Hawary, HPLC-DAD-MS/MS profiling of phenolics from Securigera securidaca flowers and its anti-hyperglycemic and anti-hyperlipidemic activities, Rev. Bras. Farmacogn., 2015, 25, 134-141.

46 J. S. Choi, M. N. Islam, M. Y. Ali, E. J. Kim, Y. M. Kim and H. A. Jung, Effects of C-glycosylation on anti-diabetic, antiAlzheimer's disease and anti-inflammatory potential of apigenin, Food Chem. Toxicol., 2014, 64, 27-33.

47 H. J. Myoung, G. Kim and K. W. Nam, Apigenin isolated from the seeds of Perilla frutescens britton var crispa (Benth.) inhibits food intake in C57BL/6J mice, Arch. Pharmacal Res., 2010, 33, 1741-1746.

48 Z. Benayad, C. Gómez-Cordovés and N. E. Es-Safi, Identification and quantification of flavonoid glycosides from fenugreek (Trigonella foenum-graecum) germinated seeds by LC-DAD-ESI/MS analysis, J. Food Compos. Anal., 2014, 35, 21-29.

49 S. D. Robert, A. A. Ismail and W. I. Wan Rosli, Trigonella foenum-graecum seeds lowers postprandial blood glucose in overweight and obese individuals, J. Nutr. Metab., 2014, 2014, 964873.

50 J. R. Mathern, S. K. Raatz, W. Thomas and J. L. Slavin, Effect of fenugreek fiber on satiety, blood glucose and insulin response and energy intake in obese subjects, Phytother. Res., 2009, 23, 1543-1548.

51 B. V. Andersen, D. V. Byrne, W. L. P. Bredie and P. Møller, Cayenne pepper in a meal: Effect of oral heat on feelings of appetite, sensory specific desires and well-being, Food Qual. Prefer., 2017, 60, 1-8.

52 R. Quirantes-Pine, L. Funes, V. Micol, A. Segura-Carretero and A. Fernandez-Gutierrez, High-performance liquid chromatography with diode array detection coupled to electrospray time-of-flight and ion-trap tandem mass spectrometry to identify phenolic compounds from a lemon verbena extract, J. Chromatogr., A, 2009, 1216, 5391-5397.

53 M. Lopez, C. V. Alvarez, R. Nogueiras and C. Dieguez, Energy balance regulation by thyroid hormones at central level, Trends Mol. Med., 2013, 19, 418-427.

54 V. Hesse, U. Spahn and W. Plenert, T4-T3 shift during the postprandial period after glucose load in obese children before and after hypocaloric diet - one factor for postprandial thermogenesis ?, Horm. Metab. Res., 1981, 13, 28-33.

55 R. S. Vijayakumar and N. Nalini, Piperine, an active principle from Piper nigrum, modulates hormonal and apo lipoprotein profiles in hyperlipidemic rats, J. Basic Clin. Physiol. Pharmacol., 2006, 17, 71-86.

56 C. De Graaf, L. S. De Jong and A. C. Lambers, Palatability affects satiation but not satiety, Physiol. Behav., 1999, 66, 681-688. 